\title{
CLÍNICA DE ESTÉTICA E BEM-ESTAR
}

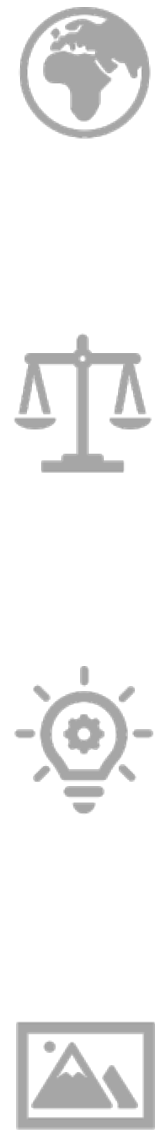

Tipologia: Misto (Hospitalar e comercial)

Doi: https://doi.org/10.47879/ed.ep.20210

Ateliê de projeto: análise e composição da forma PROFESSOR: Bruno Matos de Farias

ALUNOS: Bruna Azevedo dos Reis Silva

Luis Eduardo Marcelo Rodrigues 


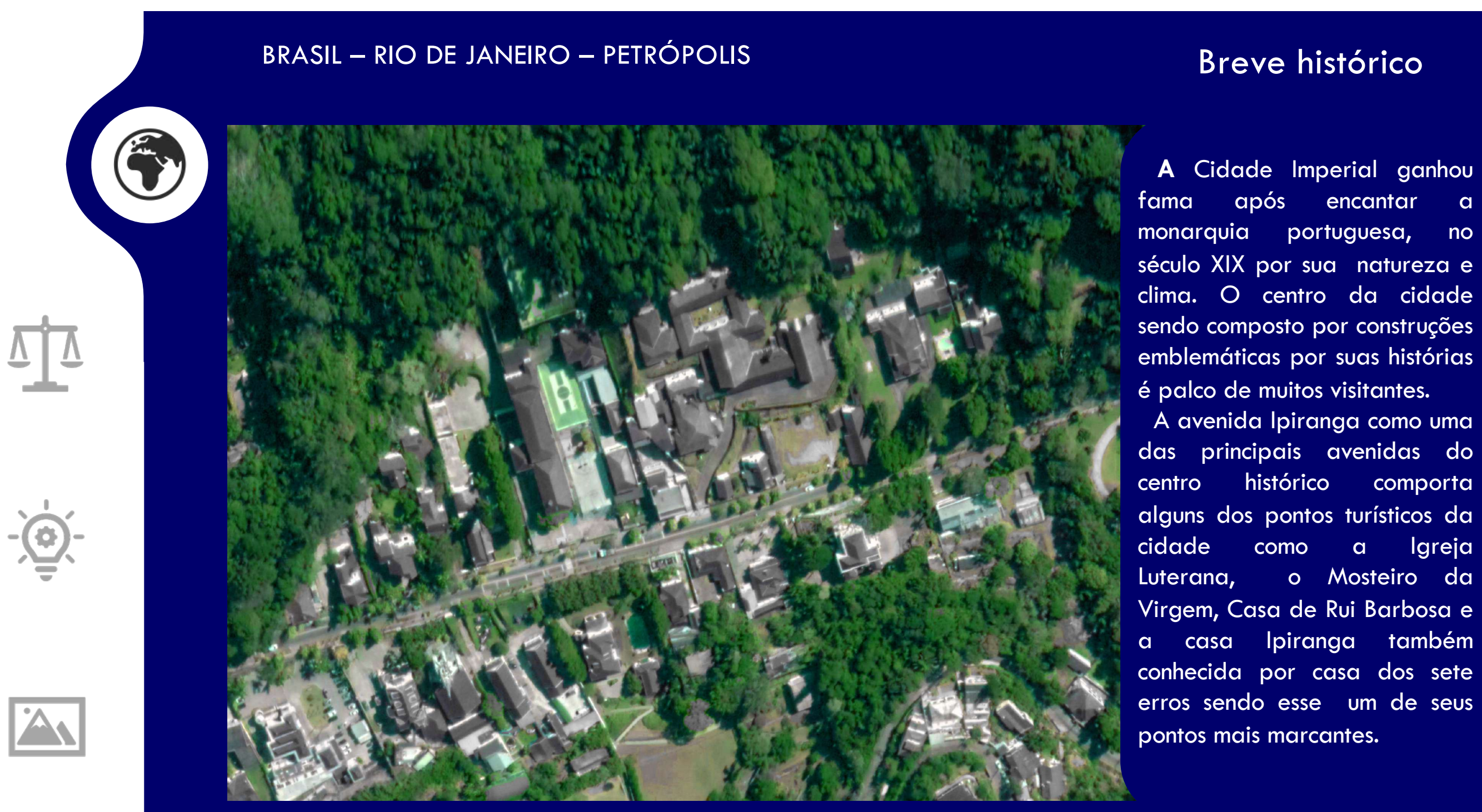

Mapa feito no Google Earth Pro e editado pelo grupo. 


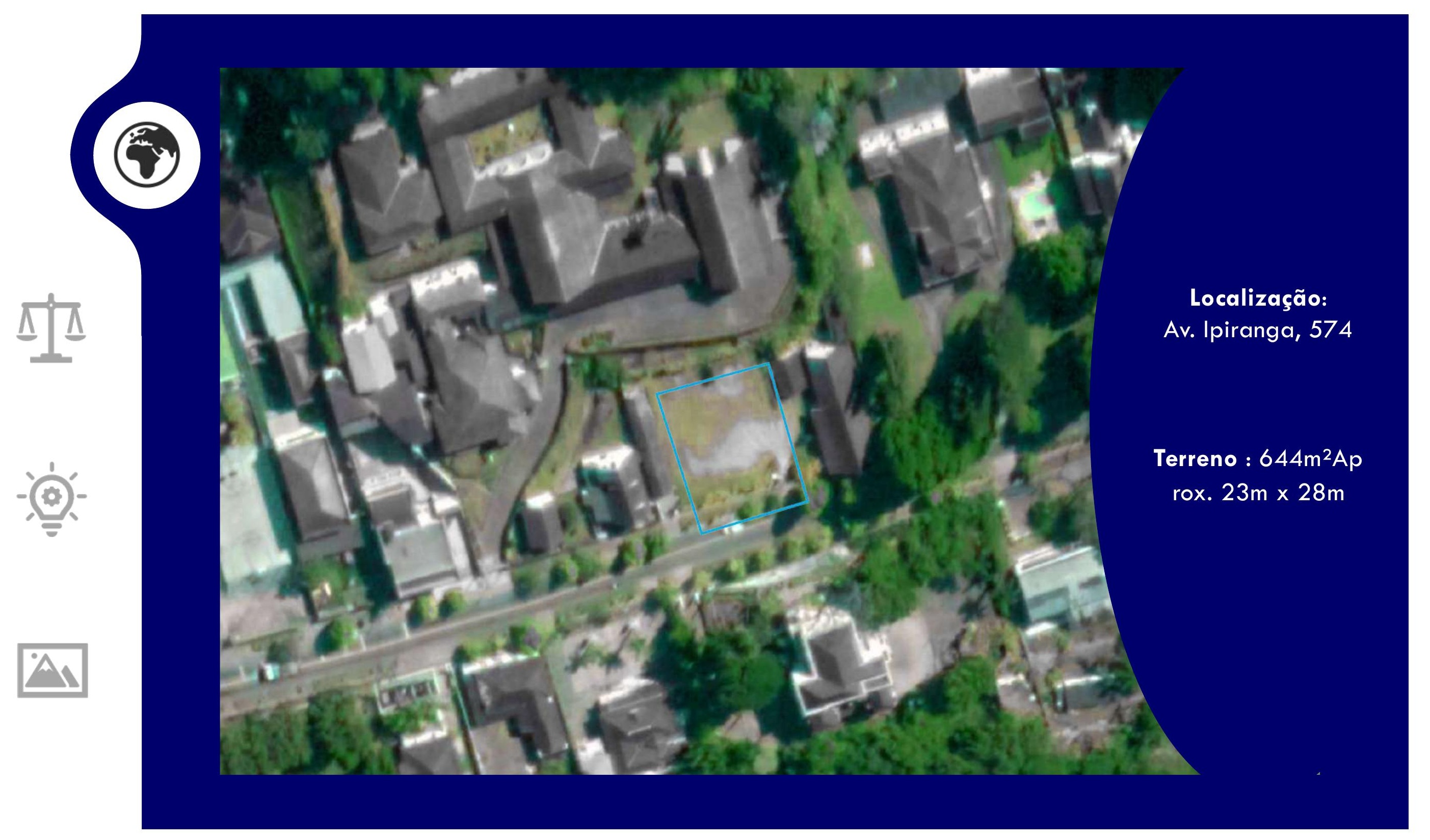




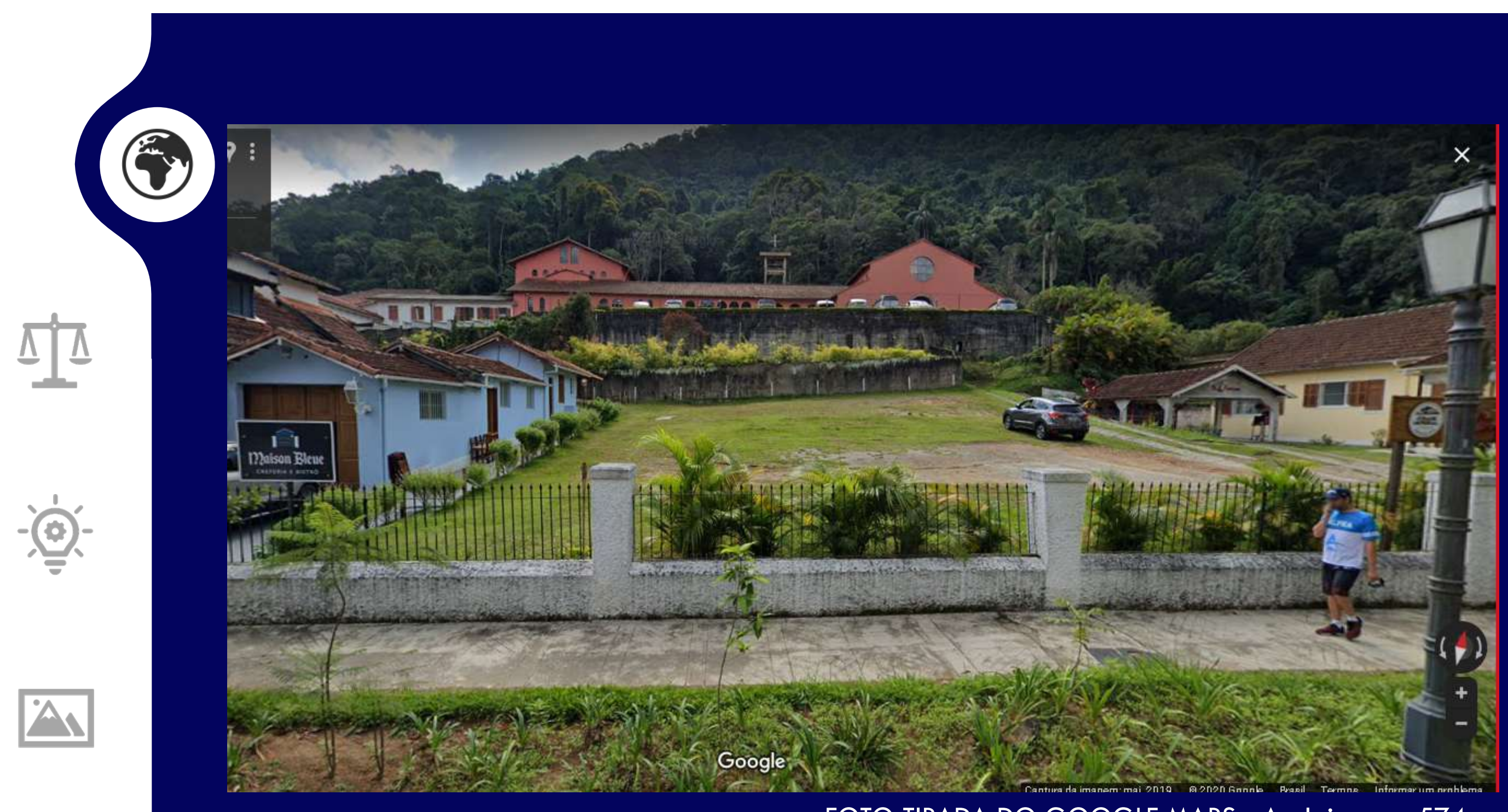

FOTO TIRADA DO GOOGLE MAPS - Av. Ipiranga, 574 


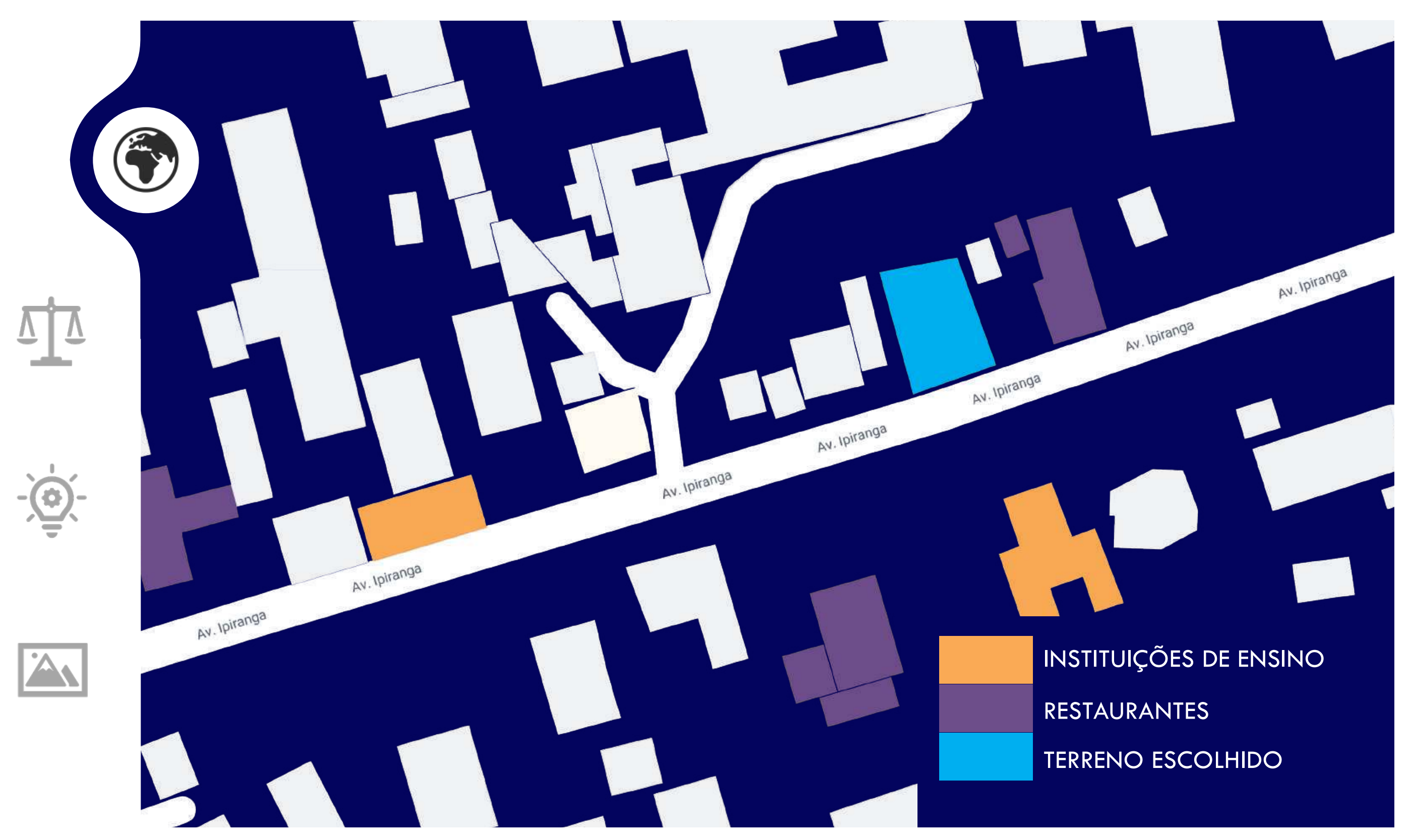




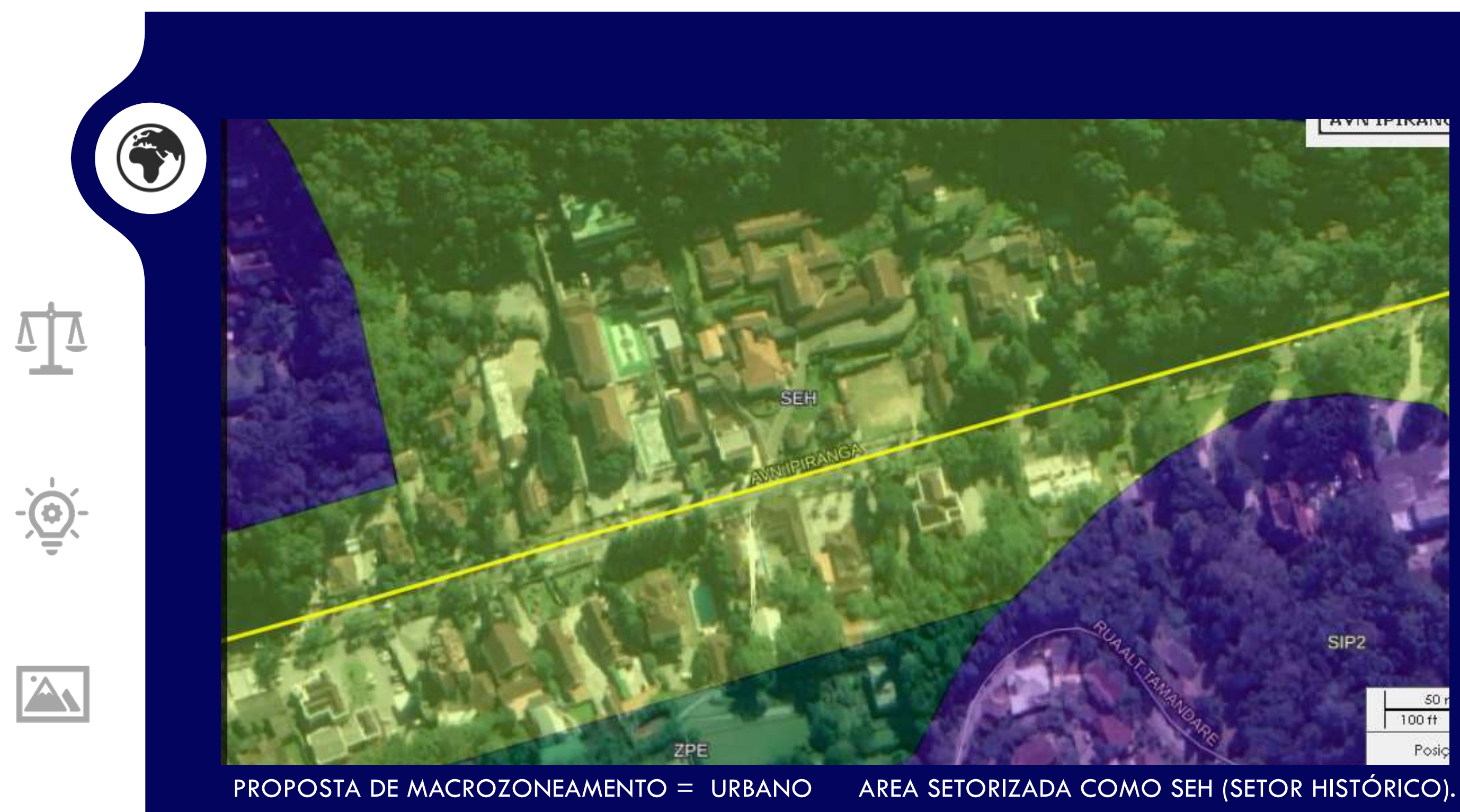




\section{LEI MUNICIPAL № 5.3931998}

Art. 10. A Zona Urbana compreende áreas já comprometidas com a ocupagã̃o urbana e com a sua expansão.

IV - Setor Histórico (SEH).

$\S 4^{\circ}$ Setor Histórico (SEH) é aquele que contém os imóveis, logradouros, sítios, praças, elementos e $\Lambda \Lambda$ monumentos tombados, em conjunto ou isoladamente, pela União, Estado e/ou Município.

Os Usos e Atividades do Setor Histórico serão determinados conforme estabelecido no art.60 Parágrafo 1.

Art. 60. Os usos e atividades adequadas determinados para cada Setor estão relacionados no Quadro de Usos e Atividades, Anexo VIII e Listagem de Categoria de Usos, Anexo X.

$\S 1^{\circ}$ A liberação dos usos e atividades em imóveis tombados pela União, Estado e Município serão objeto de análise da Comissão Permanente de Análise de Projełos.

Art. 65. No Setor Histórico (SEH) não há exigência quanto à vaga de estacionamento para os imóveis de uso comercial e/ou misto, caso exista estacionamento de uso público em um raio de $500 \mathrm{~m}$ (quinhentos metros) a partir do prédio em que se instalar a atividade.

De acordo com a lei municipal, para cada $100 \mathrm{~m}^{2}$ de área de construção é necessário possuir no minimo 1 vaga. 


\section{LEI MUNICIPAL № 5.3931998}

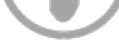

(it)

SETOR Gabarito art. 31, a)

Afast.

frontal

art. 31.

p/unifam. $13,00 \mathrm{~m}$

SUD $2 \mathrm{p} /$ multifam. $15,50 \mathrm{~m}$

\begin{tabular}{l|l} 
& $\mathrm{p} /$ indústria $15,50 \mathrm{~m}$ \\
$\mathrm{SEH}$ & $*$
\end{tabular}

b)

*Índice de

Tx.

Tx. Altura de aproveit.

ocup. "Área mín. por unidade perm. implantação

art. 31, c)

art. art. 31, e)

$\underline{31, d)}$

Res. s/restr. hotel/res.

$\begin{array}{llll}3,00 \mathrm{~m} & 1,8 & 70 \% & 40 \mathrm{~m}^{2} \text { Com. } 30 \mathrm{~m}^{2} \mathrm{c} / \mathrm{jirau}\end{array}$ $20 \mathrm{~m}^{2} \mathrm{~s} /$ jirau

SIP 1 2 pav. alt. máx. $10,00 \mathrm{~m} 3,00 \mathrm{~m}$

1,2

$60 \%$ Res. s/restr. com. $30 \mathrm{~m}^{2}$ art. 31. máxima art.

f $\quad \underline{31, g)}$

$10 \% \quad 10,00 \mathrm{~m}$

* Parâmetros definidos pela legislação Federal, Estadual e Municipal específica. 


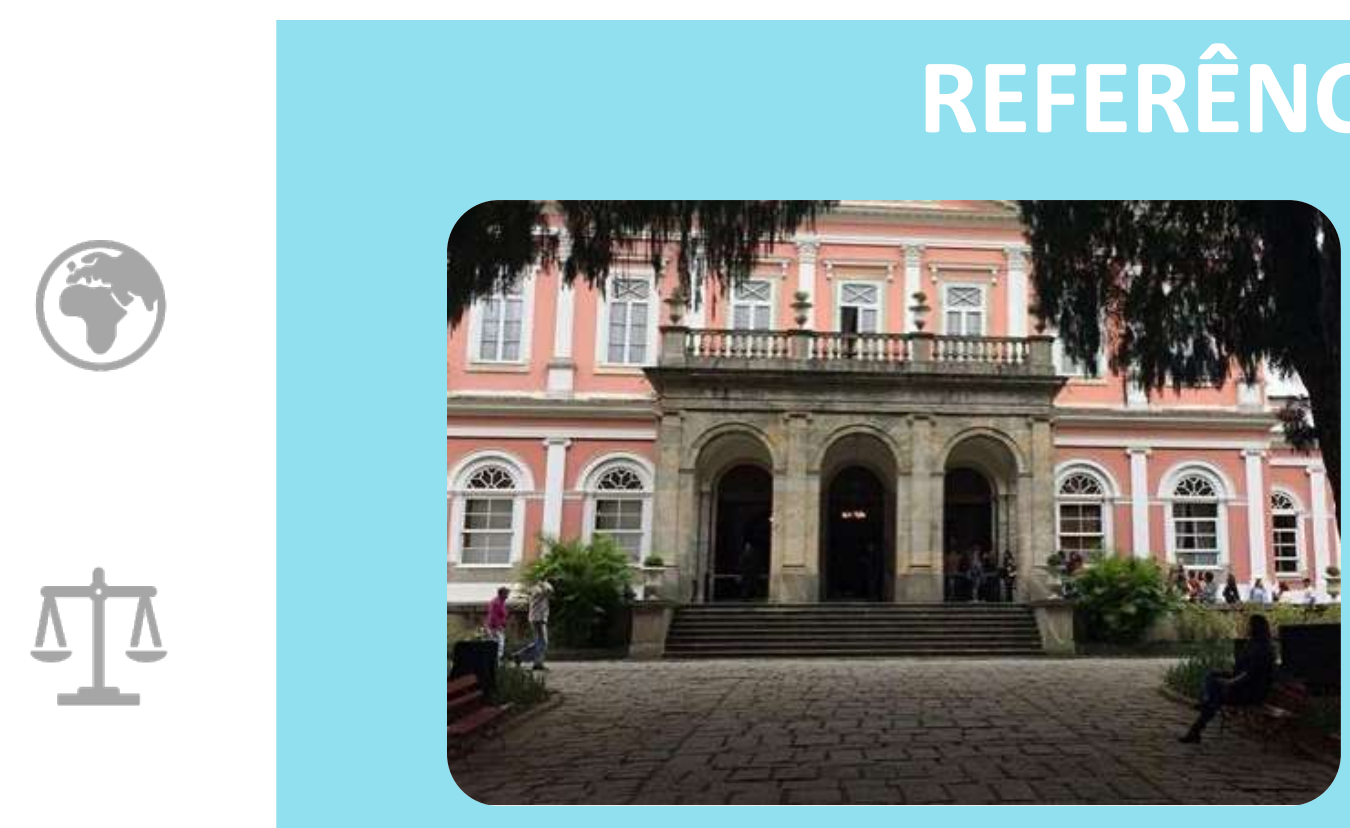

MUSEU IMPERIAL

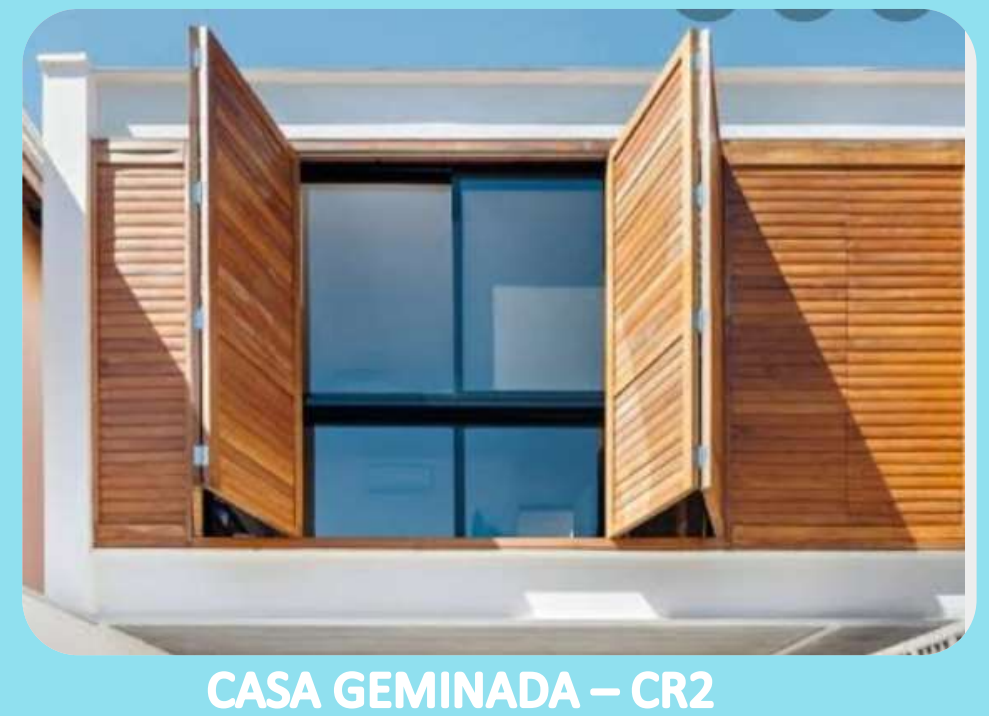

演-

$\Delta$

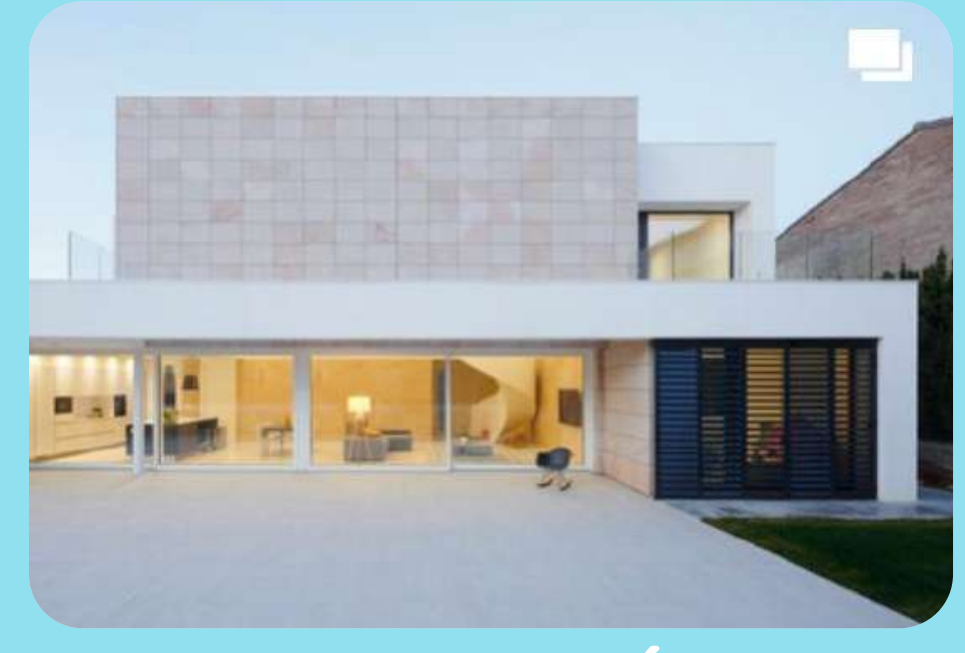

CASA IKER \& MARIA 


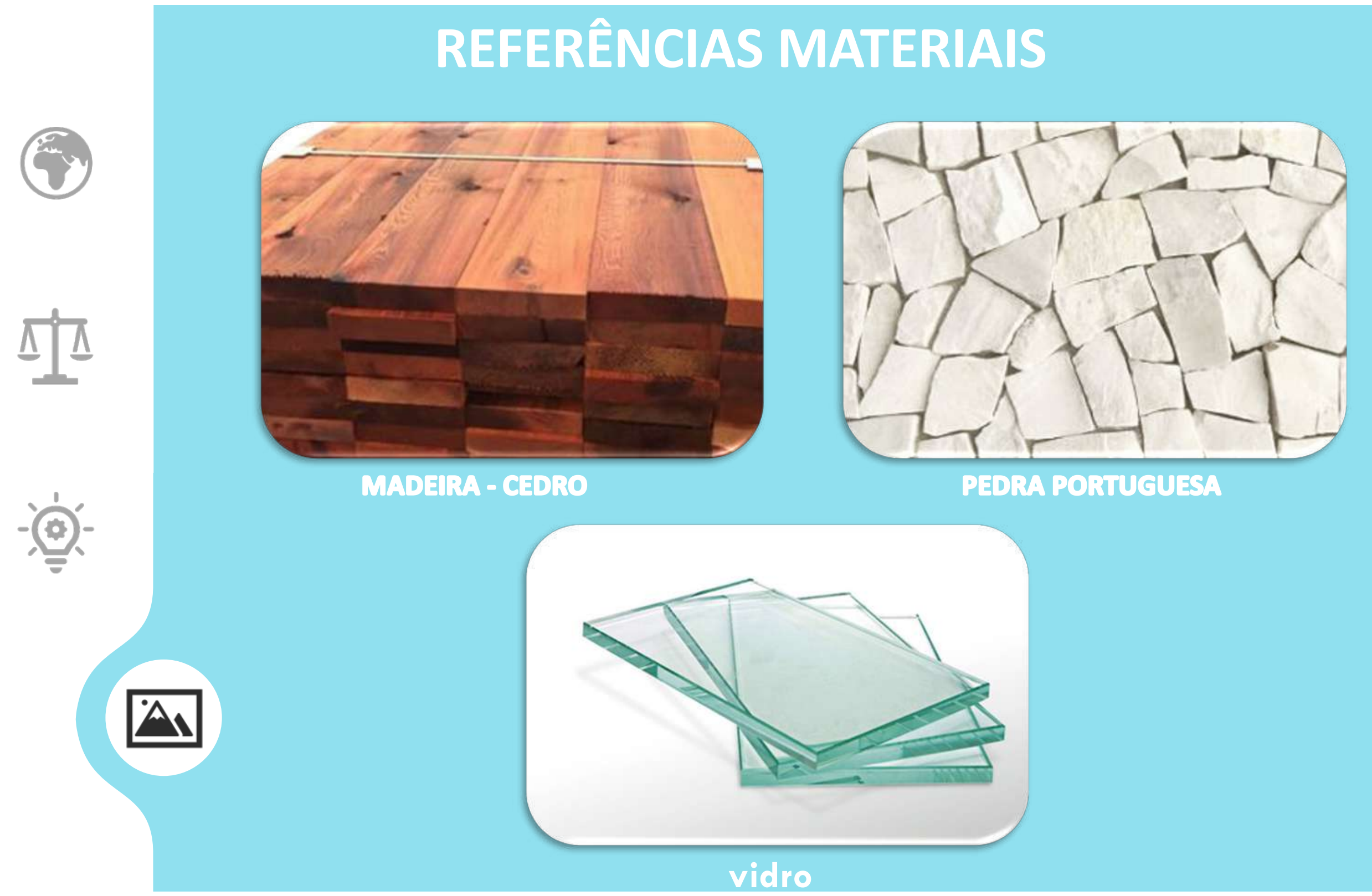




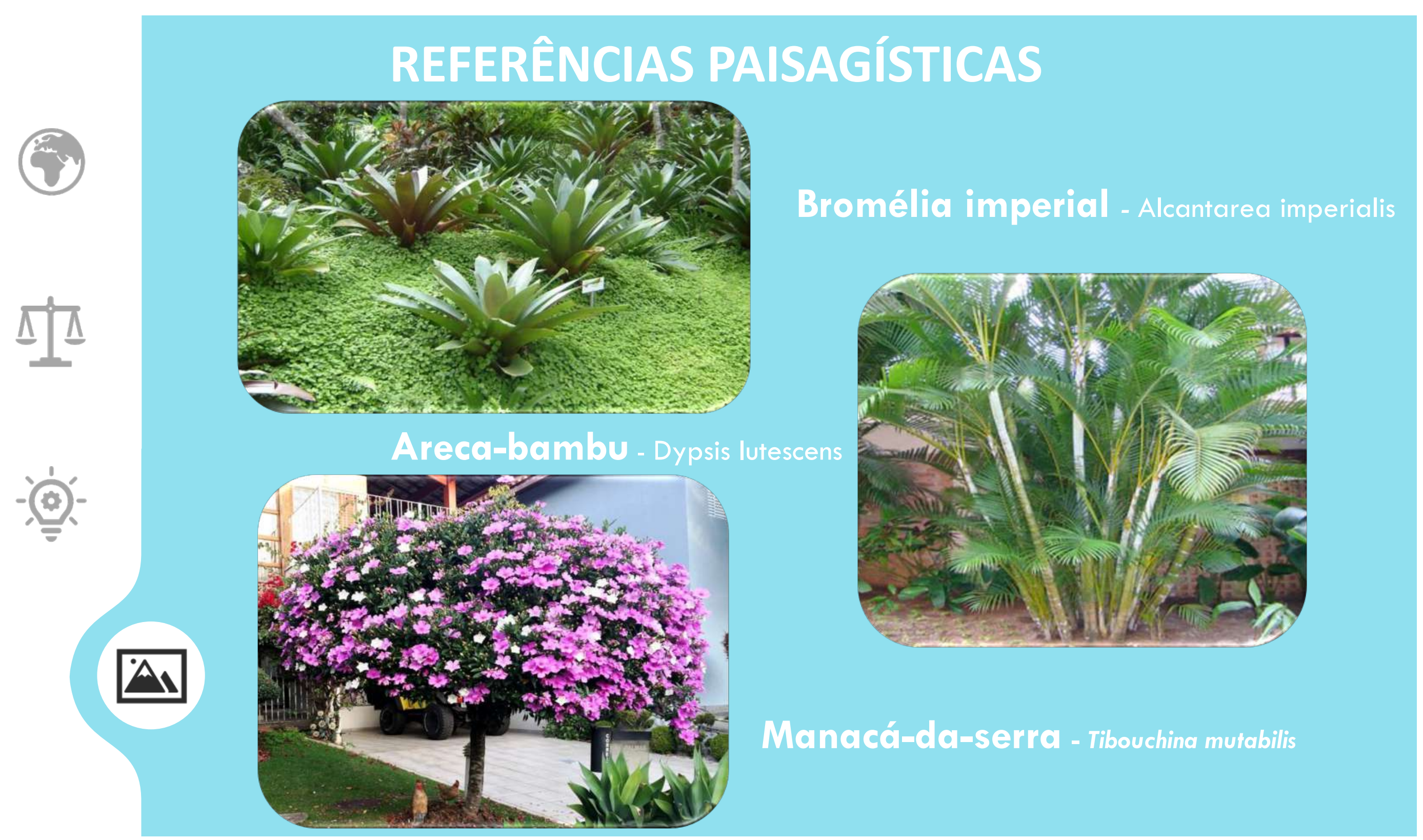




\section{CONCEITO \ PARTIDO}

\section{INTEGRAÇÃO}

- De serviços das áreas da saúde e estética

\section{Estrutura}

Aberturas

Forma e

- Da arquitetura tradicional da cidade com material 


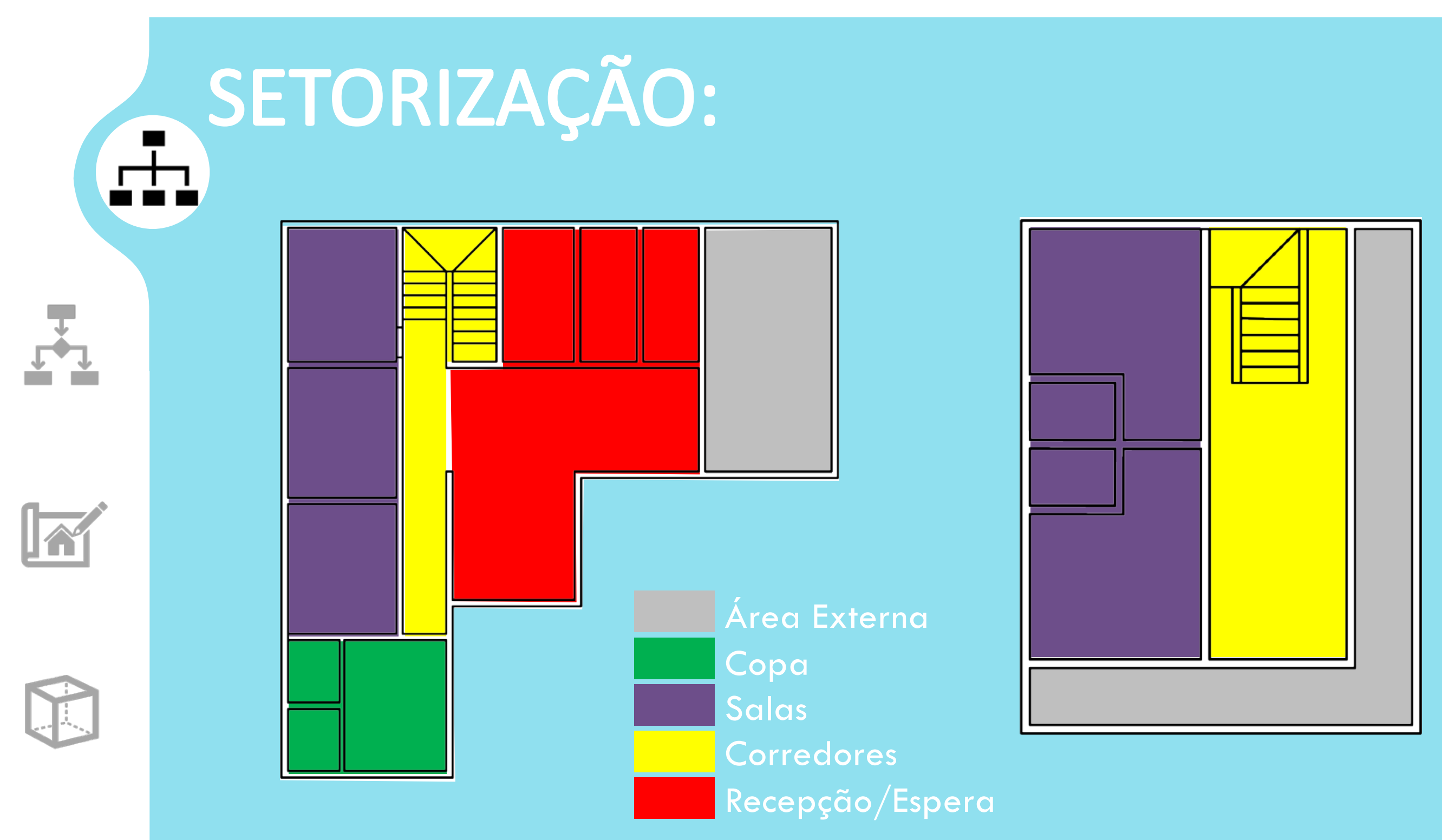




\section{H. ORGANOGRAMA:}

\section{Entrada}
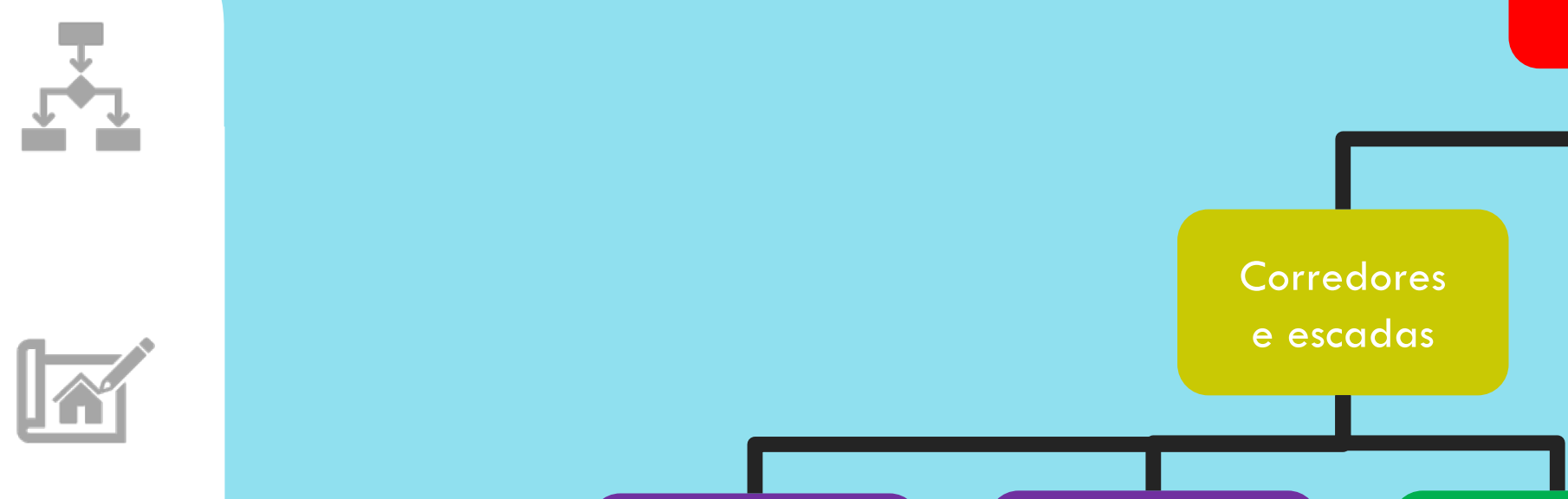

Salas de atendimento

(Pavimento 2)

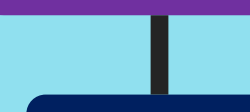

Salas de atendimento

(Pavimento 1)
Banheiros

Área externa

Banheiros 


\section{Fluxograma:}

Circulação interna(Profissionais)

Circulação exłerna (Pacientes)
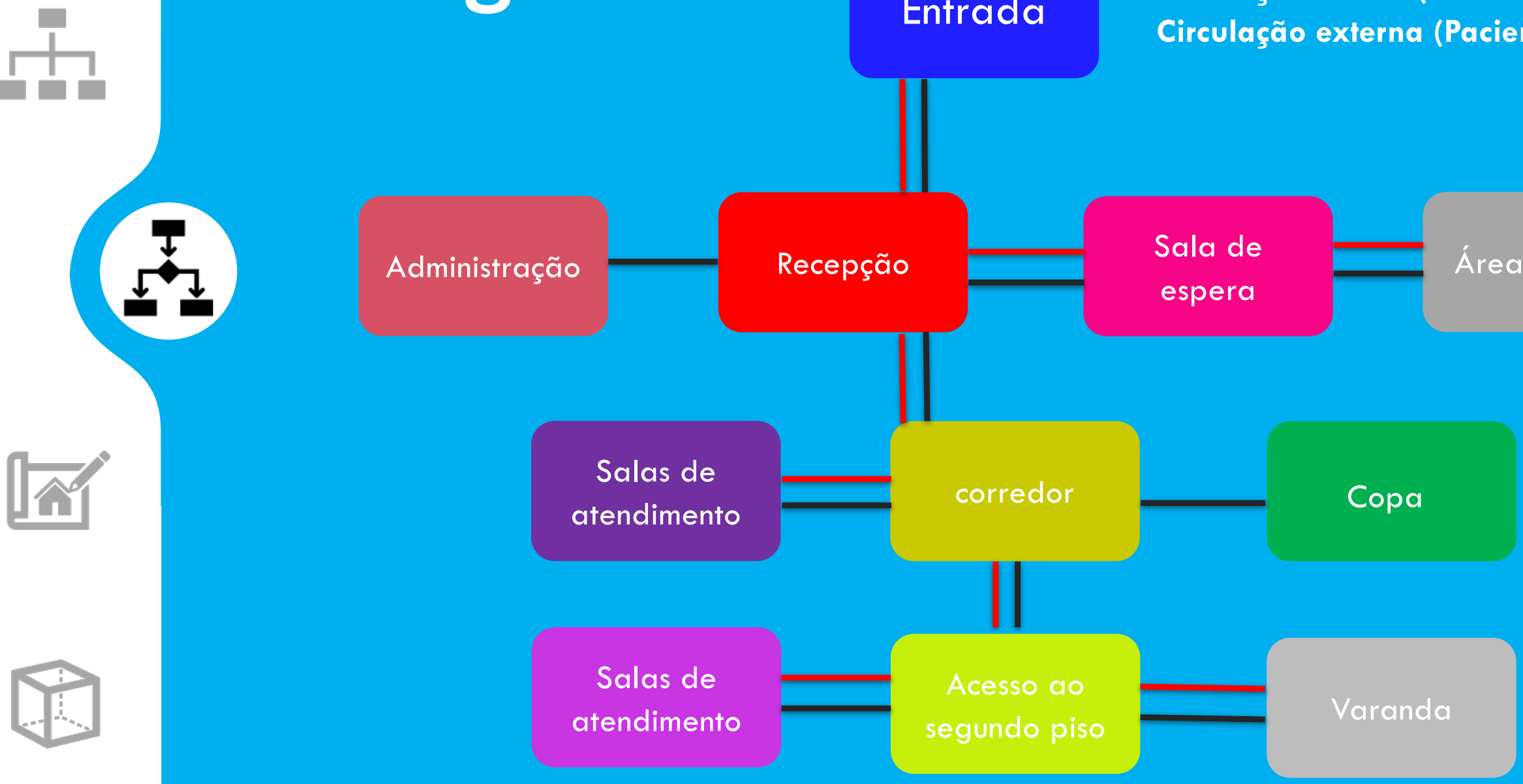


\section{MEMORIAL DESCRITIVO:}

O projeto CLÍNICA DE ESTÉTICA E BEM-ESTAR tem como principal função suprir a necessidade e manter a saúde Psicológica que á região necessita.

Alunos e responsáveis, Visitantes e Residentes poderão usufruir do espaço tendo atendimento psicológico ou adquirindo o serviço estético. 


\section{MEMORIAL JUSTIFICATIVO:}

A CLÍNICA DE ESTÉTICA E BEM-ESTAR tem muito o que adicionar à região da Av. Ipiranga pois, acrescenta diversos recursos que complementam região como: tipologia Hospitalar que oferece serviços de atendimento psicológico essencial para estudantes, residentes e turistas e a Tipologia Comercial oferecendo serviço de estética que aumentam a autoestima e bem estar além do paisagismo que enriquece o visual da região. 


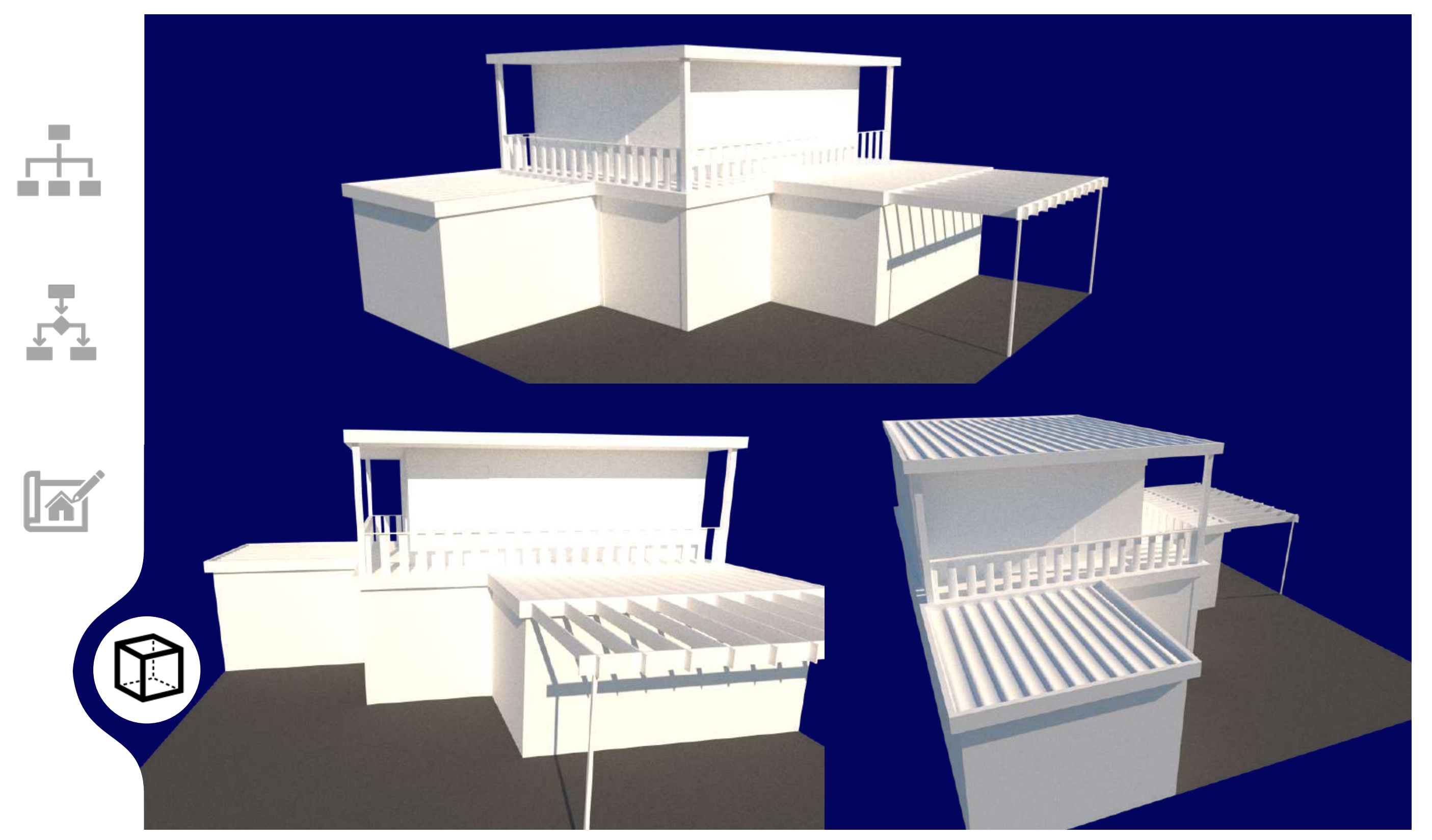




\section{Plantas:}

策

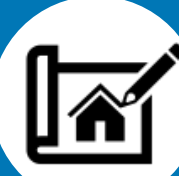

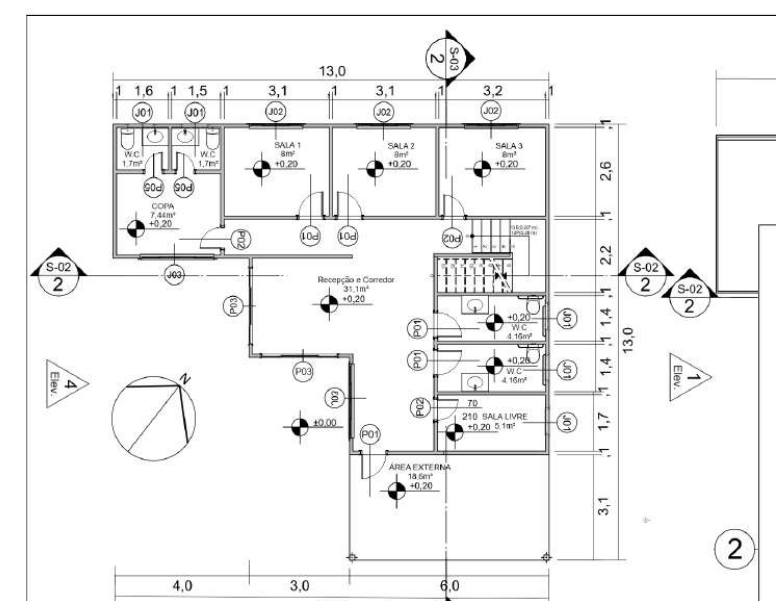

。

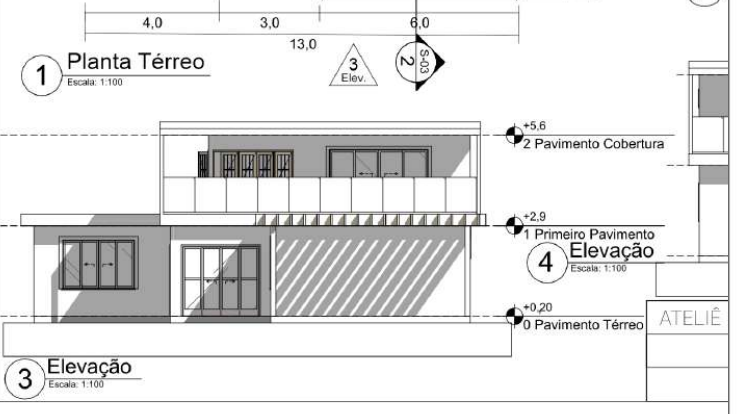

5-03 $\frac{\text { Corte }}{\text { Escala: 1:100 }}$
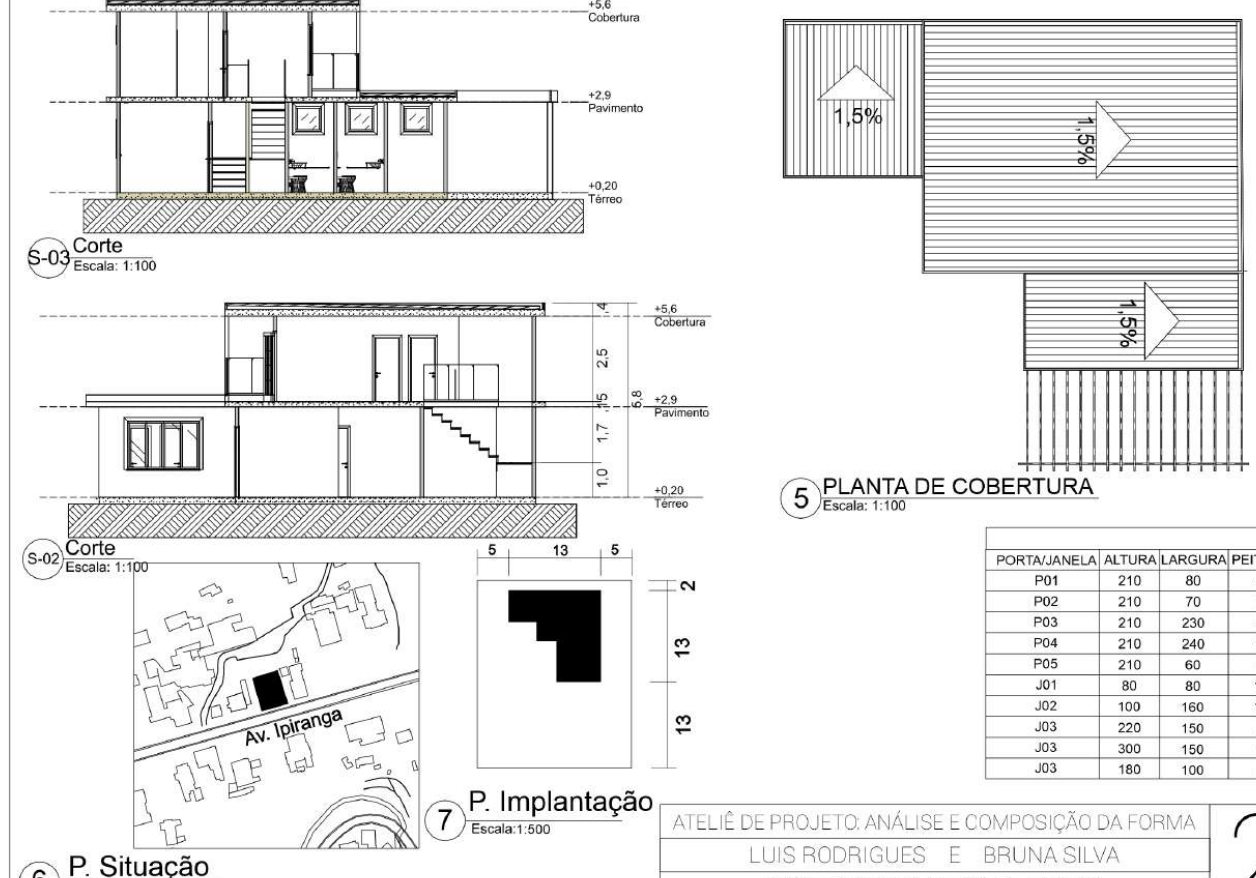

(5) PLANTA DE COBERTURA

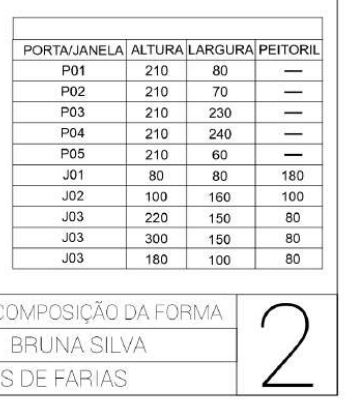




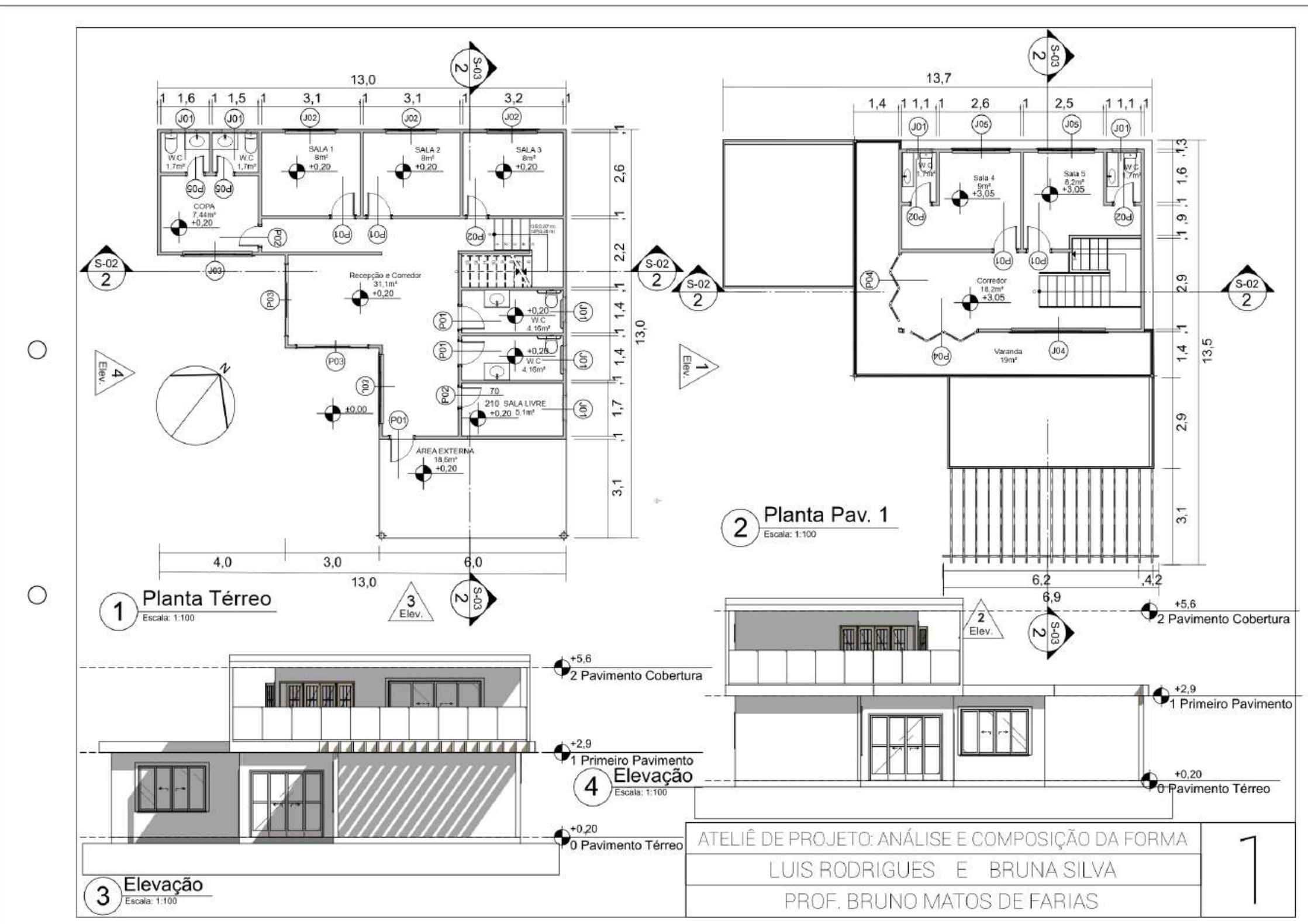




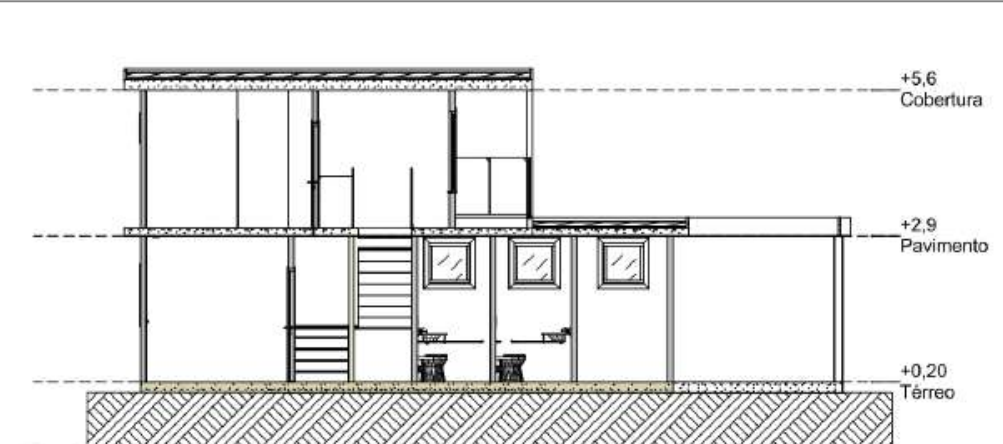

S-03 $\frac{\text { Corte }}{\text { Escala: } 1: 100}$

$\bigcirc$

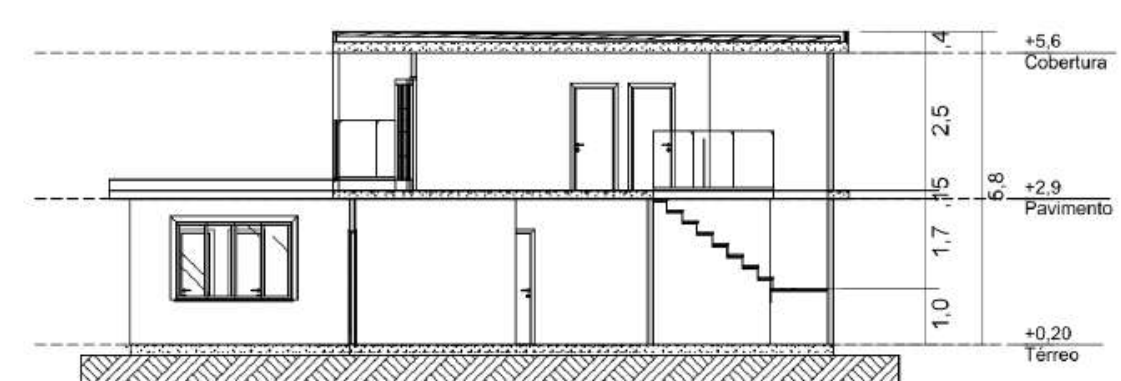

$\bigcirc$
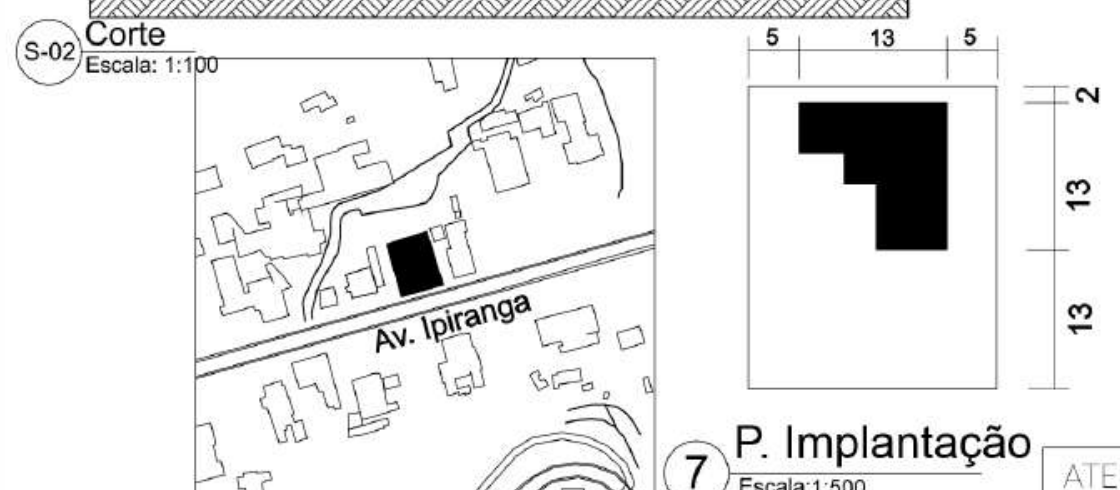

(5) PLANTA DE COBERTURA

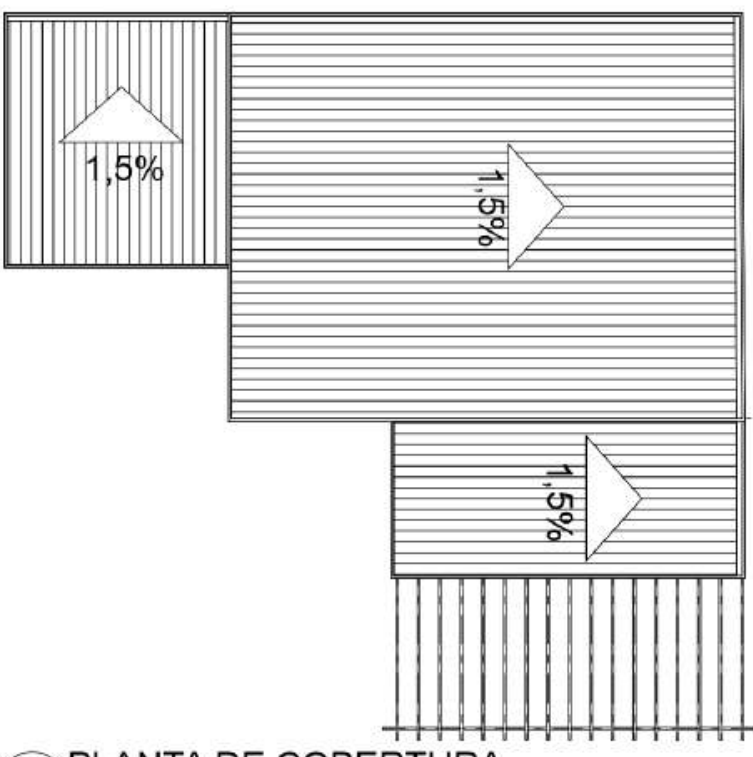

\begin{tabular}{|c|c|c|c|}
\hline \multicolumn{5}{|c|}{} \\
\hline PORTA/JANELA & ALTURA & LARGURA & PEITORIL \\
\hline P01 & 210 & 80 & - \\
\hline P02 & 210 & 70 & - \\
\hline P03 & 210 & 230 & - \\
\hline P04 & 210 & 240 & - \\
\hline P05 & 210 & 60 & - \\
\hline $\mathrm{J} 01$ & 80 & 80 & 180 \\
\hline J02 & 100 & 160 & 100 \\
\hline$J 03$ & 220 & 150 & 80 \\
\hline $\mathrm{J} 03$ & 300 & 150 & 80 \\
\hline J03 & 180 & 100 & 80 \\
\hline
\end{tabular}

(6) P. Situação

7 P. Implantação

ATELIE DE PROJETO: ANÁLISE E COMPOSIÇÃO DA FORMA LUISRODRIGUES E BRUNASILVA PROF. BRUNO MATOS DE FARIAS

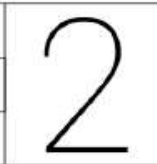




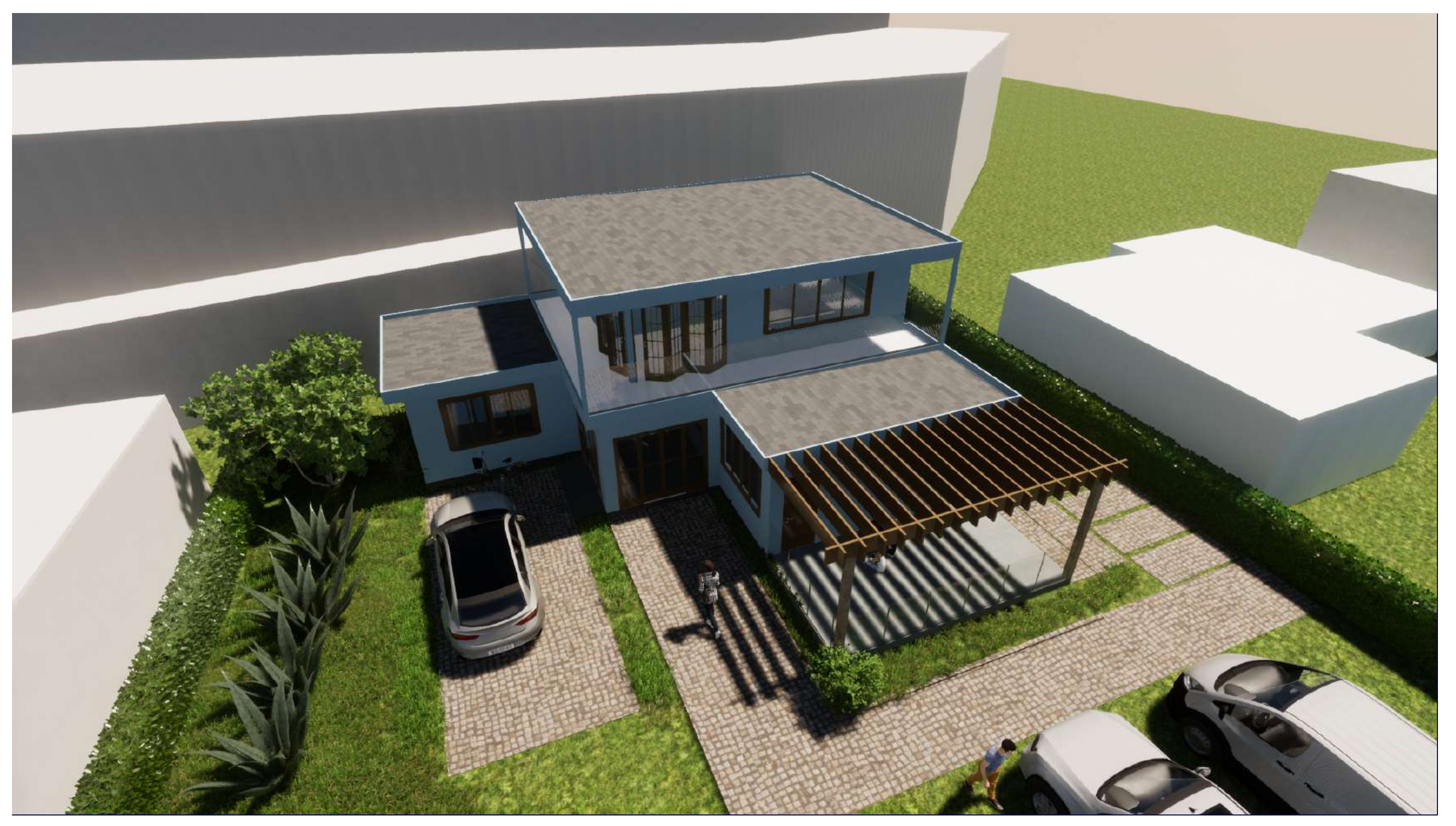




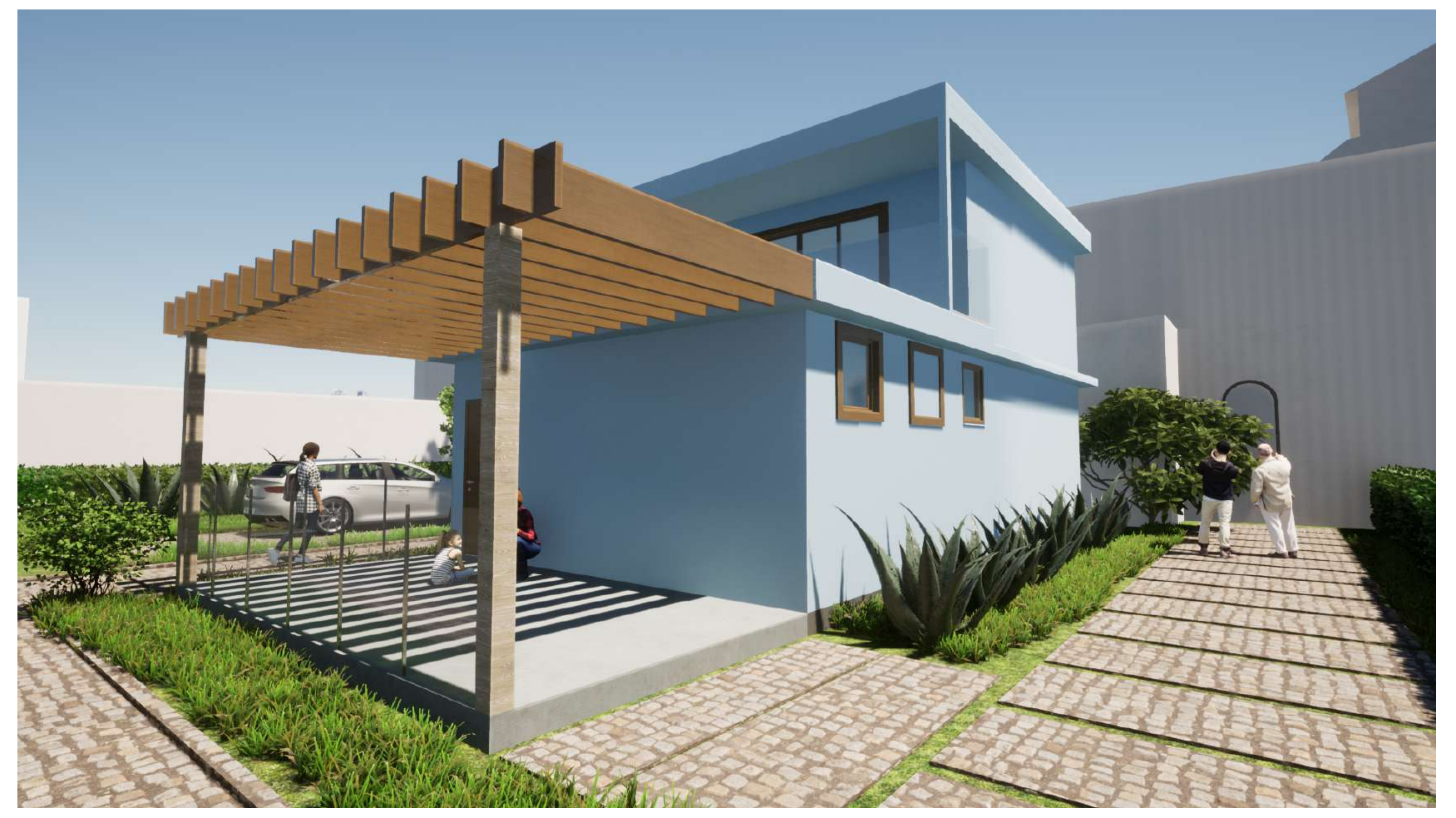




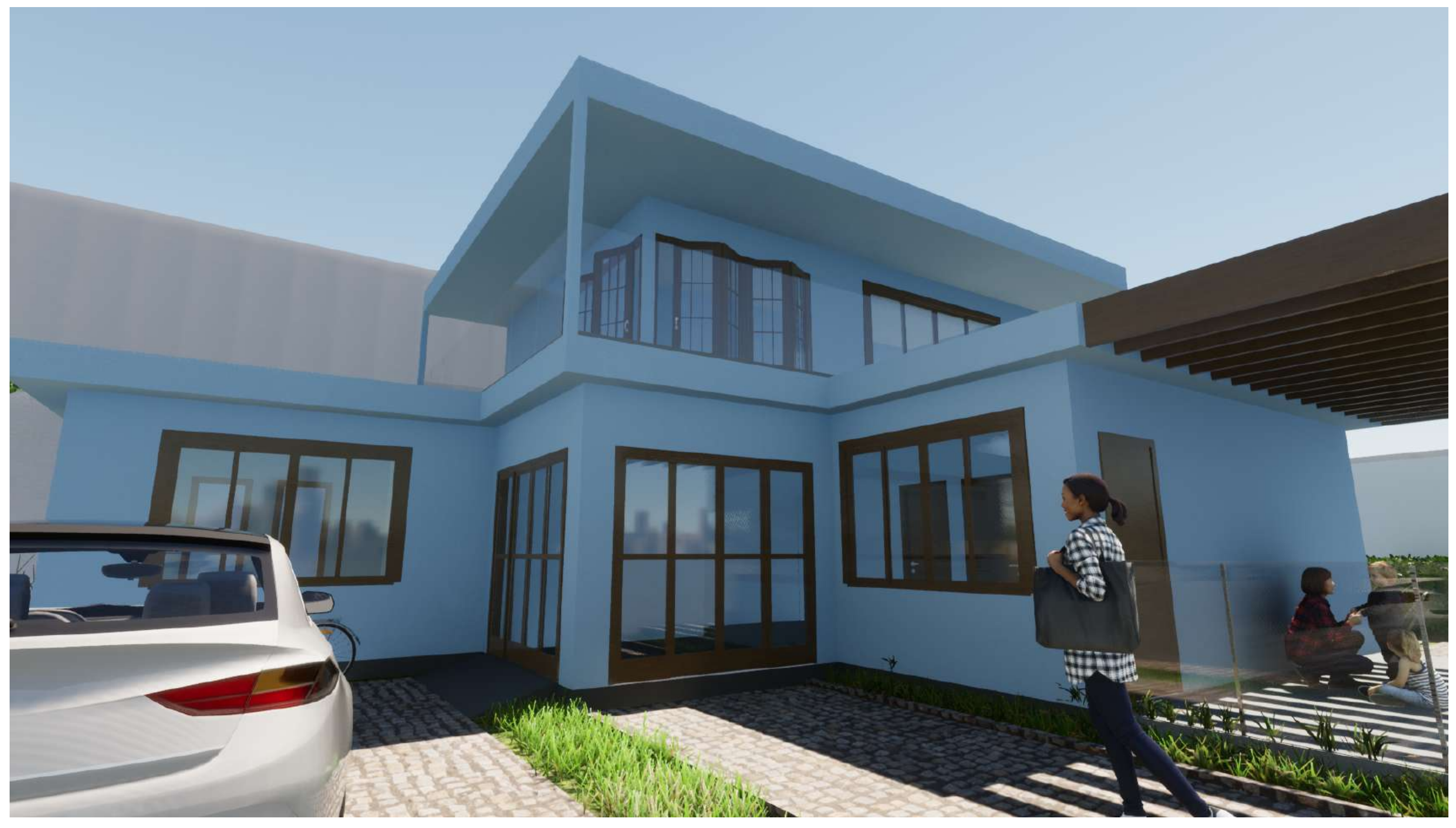




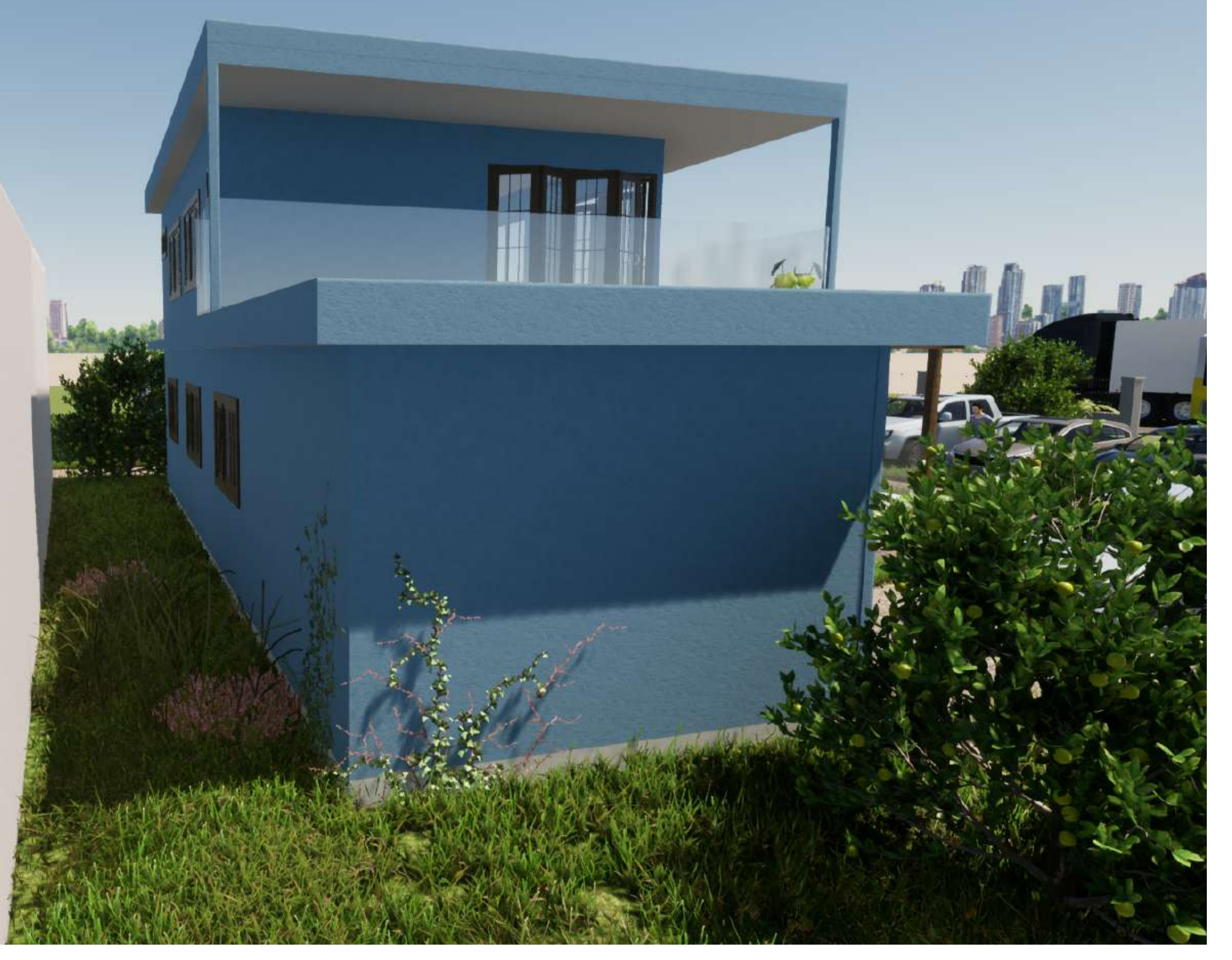




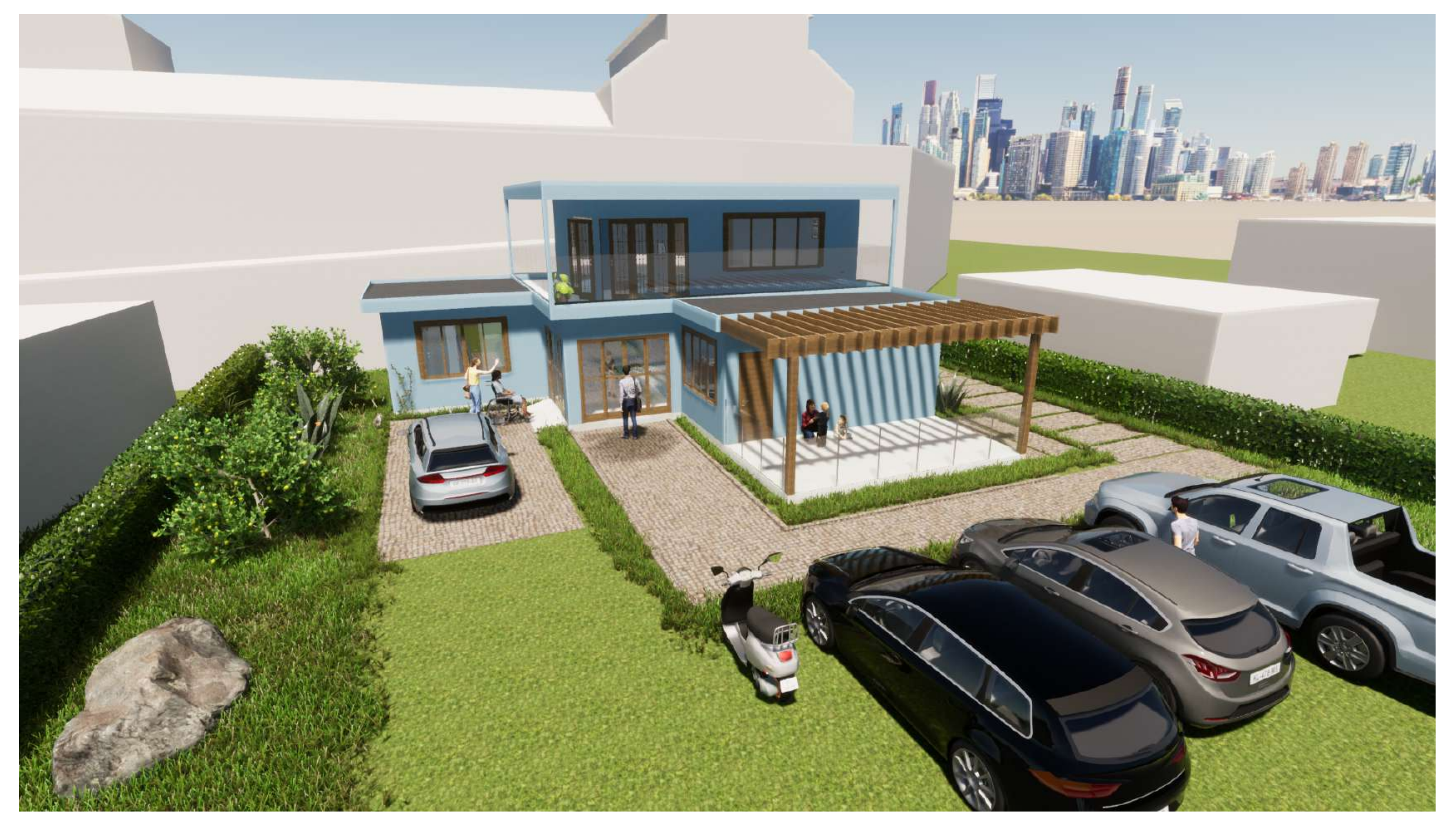




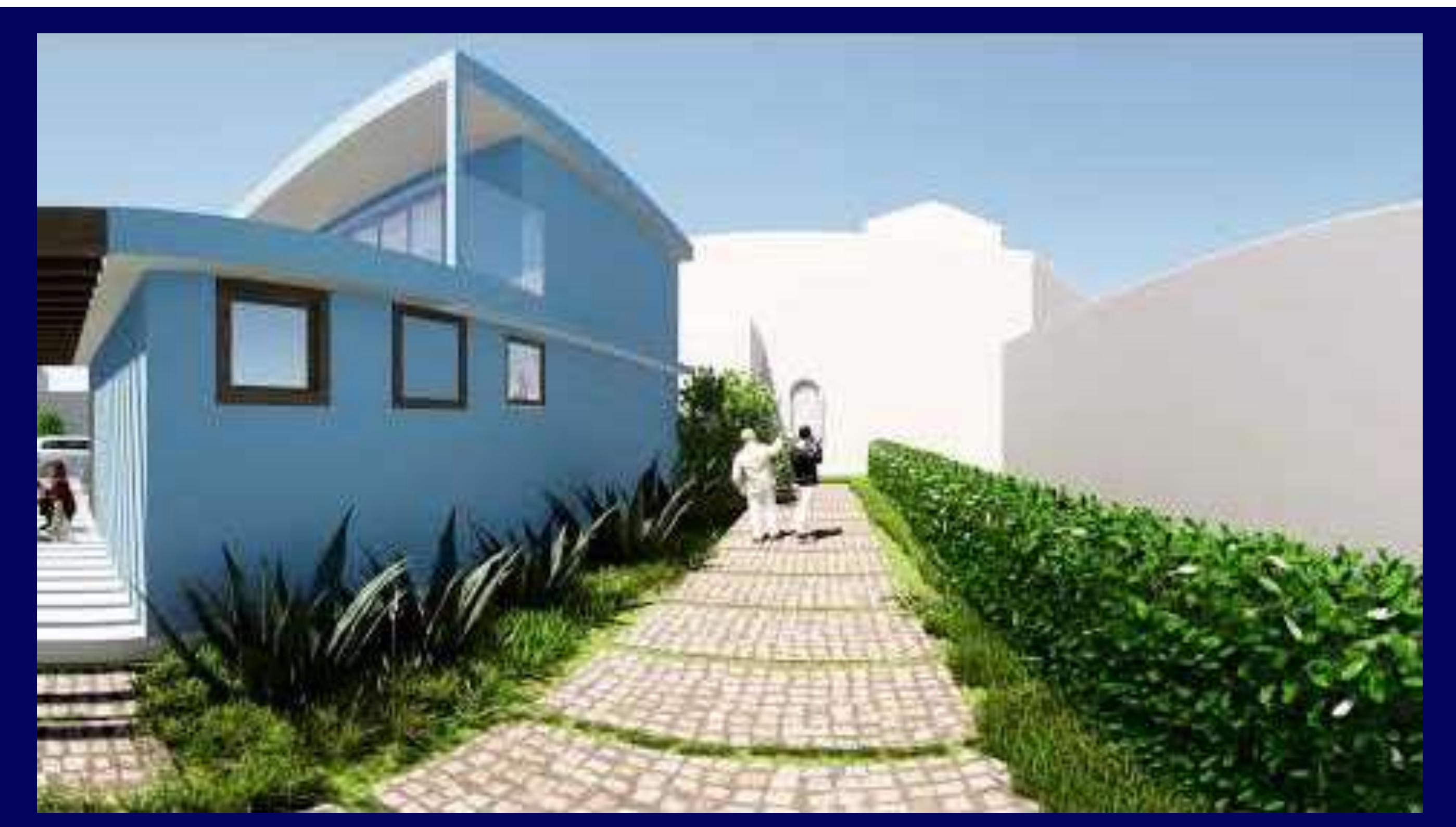


https://www.archdaily.com.br/br/869050/casa-geminada-cr2-arquitetura

http://www.aconteceempetropolis.com.br/2017/04/03/voce-conhece-o-vale-do-amor/

https://www.anualdesign.com.br/goias/projetos/1980/casa-aldeia-do-vale/,

https://www.archdaily.com.br/br/office/levisky-arquitetos-estrategia-urbana

https://casaclaudia.abril.com.br/casas-apartamentos/arquiteta-compra-casa-do-vizinho-em-trancosopara-ganhar-area-de-lazer/

https://www.archdaily.com.br/br/940310/casa-iker-and-maria-tangram-arquitectura-plusdiseno? ad medium=gallery

http://sig.petropolis.ri.gov.br/ 